\title{
The problem of insignificant hands
}

\author{
Frank Hindriks ${ }^{1}$
}

Accepted: 29 June 2021/Published online: 17 August 2021

(C) The Author(s) 2021

\begin{abstract}
Many morally significant outcomes can be brought about only if several individuals contribute to them. However, individual contributions to collective outcomes often fail to have morally significant effects on their own. Some have concluded from this that it is permissible to do nothing. What I call 'the problem of insignificant hands' is the challenge of determining whether and when people are obligated to contribute. For this to be the case, I argue, the prospect of helping to bring about the outcome has to be good enough. Furthermore, the individual must be in a position to increase the probability of its being brought about to an appropriate extent. Finally, I argue that when too few are willing to contribute, people may have a duty to increase their number. Thus, someone can be obligated to contribute or to get others to contribute. This prospect account is consistent with Kantianism, contractualism and rule consequentialism but inconsistent with act consequentialism.
\end{abstract}

Keywords Collective responsibility - Duty to mobilize · Feasibility · Problem of insignificant hands · Problem of many hands · Redundancy

\section{Introduction}

Many moral problems involve many hands. Striking examples include tragedies of the commons, including overgrazing, deforestation and global warming (Hardin, 1968). Such 'problems of many hands' can be solved only if several individuals contribute (Thompson, 1980). To solve such a problem, a collection of individuals

Frank Hindriks

f.a.hindriks@rug.nl

1 Faculty of Philosophy, University of Groningen, Oude Boteringestraat 52, 9712GL Groningen, The Netherlands 
has to generate a beneficial outcome or prevent a harmful outcome. Even though the overall outcome is morally desirable, however, individual contributions to it need not be morally significant as such. For instance, a single individual can reduce her greenhouse gas emissions by turning off the air conditioning at night. It is unlikely that she will thereby prevent a climate harm, however. ${ }^{1}$ In such situations, a single individual contribution to the outcome — an individual 'hand' - is morally insignificant in the exact same sense in which the overall outcome is morally significant: it does not generate any of the relevant benefits or prevent any of the harms at issue. This makes it difficult to see how contributing could be required. I will in fact assume that, intuitively, it is rarely acceptable to do nothing. The challenge is to determine whether and how this intuition can be preserved. I call this challenge 'the problem of insignificant hands.' 2

Solutions to this problem can be located on a spectrum depending on how many individuals are required to contribute. The extremes are (almost) nobody and (almost) everybody. Walter Sinnott-Armstrong (2005) defends what I call 'the minimal solution.' He considers a number of 'joyguzzlers': individuals who drive their gas-guzzling cars for fun on Sunday afternoons (see also Kingston \& SinnottArmstrong, 2018). He argues that nobody is obligated to stop joyguzzling because no one person emits enough greenhouse gasses to cause harm on their own. Shelly Kagan (2011) defends 'the maximal solution' when he argues that the expected utility of the outcome will (usually) be larger than the costs of contributing to it, for instance by refraining from joyguzzling. He proposes that everybody for whom this holds should contribute. The maximal solution can also be defended from a deontological perspective. In this spirit, Matthew Braham and Martin van Hees (2012) argue that all joyguzzlers are blameworthy.

Each of these extreme solutions faces a substantial problem. The minimal solution flies in the face of common sense. People carpool, recycle, and form human chains to rescue drowning swimmers. Apparently, they believe that they can make a meaningful contribution at least some of the time. But if the minimal solution is correct, then they are wrong about this. The maximal solution implies that people should contribute even when there is no chance that the outcome will materialize. But under such circumstances, contributing is in some sense futile. This makes it difficult to see how individuals could be required to make a contribution. In light of this, I develop an intermediate or moderate solution that avoids both problems. Its point of departure is the notion of a successful contribution, which is a contribution that helps bring about the outcome. Its core claim is that contributing is required only if the prospect of success is good enough. In contrast to the minimal solution, this 'prospect account' entails that people can be required to contribute. And, in contrast to the maximal solution, it is obligatory to do so only if there is a chance that the outcome will come about.

\footnotetext{
1 See also Sinnott-Armstrong (2005). Note that over an entire lifespan, affluent individuals do cause substantial harm (Nolt, 2011).

2 This is also known as 'the problem of inconsequentialism' (Sandler, 2009), 'the problem of inefficacy' (Nefsky, 2019), and 'the problem of collective harm' (Nefsky, 2011). See below for more on the advantages of my choice of terminology.
} 
I present the prospect account in Sect. 3. In Sect. 4, I consider how responsive it is to the feasibility of the outcome and to the redundancy of some of the contributions. I go on to argue that when too few are willing to contribute, individuals can have an obligation to increase their number. The point of mobilizing others is to ensure that the prospect of success is good enough. In Sect. 5, I argue that the prospect account is consistent with Kantianism, contractualism and rule consequentialism but inconsistent with act consequentialism. Before I get to this, however, I introduce the problem more fully.

\section{The problem}

The problem of insignificant hands concerns collective outcomes, which are outcomes that come about only if several individuals contribute. The problem arises in what I call 'insignificant hands situations,' which are defined by two further features. First, the collective outcome is morally desirable or significant ('collective significance'). Either it is beneficial or it provides a neutral alternative to a harmful outcome. Second, a single individual contribution to that outcome-an individual hand-is as such morally insignificant ('individual insignificance'). This means that it does not generate any of the relevant benefits or prevent any of the harms at issue. The problem of insignificant hands is the challenge of determining why anyone would be obligated to contribute to a morally significant outcome, even though the effect of an isolated individual contribution is morally insignificant. Solving it requires settling whether and when an individual ought to contribute to an outcome in an insignificant hands situation. ${ }^{3}$

My use of the term 'individual hand' for an individual contribution to a collective outcome is inspired by the problem of many hands. Dennis Thompson (1980), who coined the term, was troubled by the fact that when individuals cooperate within the context of an organization, it is difficult if not impossible to disentangle their contributions to an actual outcome. As he saw it, the crux of the problem was that in relevant situations, it is 'difficult even in principle to identify who is morally responsible' (1980, p. 905). The first and main difference between the problem of insignificant hands and the problem of many hands is that the latter can arise even if individual hands are not good or bad in themselves. Furthermore, Thompson was concerned with backward-looking responsibility, or with whether people could be praised or blamed for their contributions. My focus, by contrast, is on forwardlooking responsibility, or on obligations. Finally, Thompson was concerned with organized collectives, whereas I focus on unorganized collectives. ${ }^{4}$

The following two examples illustrate the problem of insignificant hands:

\footnotetext{
3 An action causally contributes to an outcome exactly if it is a necessary element of a set of actions that are sufficient for it. Thus, a contribution is a NESS-condition for the outcome (Hart \& Honoré, 1959; Mackie, 1974; Wright, 1988).

4 According to a widely accepted account, organized collectives differ from unorganized collectives in that the former employ a collective decision procedure (French, 1984; List \& Pettit, 2011; Hindriks 2018). See Van de Poel et al. (2015) for a discussion of the problem of many hands in relation to organized collectives.
} 
Three Nurses. Three nurses, Noah, Omar, and Pablo, are caring for a patient who is severely ill. Each has access to a different kind of medicine. The patient will survive only if each of them administers the medicine to which he has access. Joyguzzlers. A number of people living in an area occasionally drive their gasguzzling cars for fun. Each can stop doing so and thereby reduce greenhouse gas emissions. However, the harm they cause will decrease only if most of them stop driving their cars for fun. (Sinnott-Armstrong, 2005)

Both examples concern individual hands situations. The survival of the patient and the lives of those affected by global warming are morally significant collective outcomes (collective significance). Furthermore, isolated contributions will not have morally desirable effects (individual insignificance). This holds for a single nurse who administers a drug as well as for a joyguzzler who refrains from engaging in the activity on his own initiative.

What is distinctive about Joyguzzlers is that it is an instance of the tragedy of the commons (Hardins, 1968; Ostrom, 2015). As such, it concerns a common resource that is non-excludable but rival in consumption (Mankiw, 2013). In this example, the common resource is the atmosphere or its capacity 'to absorb our waste gases without changing the planet's climate in harmful ways' (Singer, 2006, p. 418). Greenhouse gas emissions can give rise to a wide range of climate harms, including extreme weather events. To make the example more concrete, I will assume that the expected emissions will increase the severity of a storm to the point of having lethal consequences.

Contrasting this example to Three Nurses will turn out to be useful for a number of reasons. For one, it shows that the causal effects of individual contributions are not always marginal, as is commonly assumed. Whereas Avram Hiller (2011) describes such contributions as 'causally insignificant,' Three Nurses reveals that in some cases, the effects of individual contributions can be rather substantial. This suggests that the real problem is the moral insignificance of (isolated) individual contributions. Furthermore, insignificant hands cases often trigger a strong intuition that people ought to contribute. Even Sinnott-Armstrong (2005) admits that it is prima facie plausible to say that joyguzzlers should refrain from engaging in their activity, although he goes on to argue that joyguzzling is permissible after all. The intuition that each of the nurses in Three Nurses should administer their drugs is unassailable, however. This raises the stakes of finding a non-skeptical solution to the problem.

In the minimal solution, almost nobody is obligated to contribute (SinnottArmstrong, 2005; Tannsjo, 1989). ${ }^{5}$ In the maximal solution, by contrast, almost everybody is obligated to do so (Kagan, 2011; Murphy, 2000). ${ }^{6}$ The claim is that in

\footnotetext{
5 Sinnott-Armstrong (2005) defends two claims. First, individuals are not obligated to refrain from activities such as joyguzzling. Second, they should encourage their governments to make them illegal. This second claim is meant to mitigate his skepticism about climate duties and qualifies his commitment to the minimal solution. However, as I discuss in Sect. 4.3, there is reason to doubt that he can coherently combine it with the first claim.

${ }^{6}$ Braham and van Hees (2012) defend the maximal solution for backward-looking responsibility. Using the notion of a NESS-condition, they argue that in principle, everybody who contributes to a collective harm is blameworthy.
} 
principle, everybody who can contribute ought to do so. The main difference between the two concerns their causal presuppositions: causal control versus causal contribution. ${ }^{7}$ Before anyone has contributed, no one has control over a collective outcome. Once two of the nurses in Three Nurses have already administered their drugs, however, the third has control over whether the patient lives or dies. Typically, everybody is able to contribute to a collective outcome. In this case, exceptions are due to other presuppositions. Someone who can contribute will be exempted, for instance, if she is not in a position to know that she is contributing to a pending harm.

But why does each of the extreme solutions have some appeal? The key thing to appreciate is that the two defining features of insignificant hands situations pull in opposite directions. Collective significance makes it attractive to regard contributing as obligatory. By contrast, individual insignificance makes it attractive to think that it is permissible not to contribute. This explains, at least in part, why solving the problem of insignificant hands is so difficult. To make this more vivid, consider collective harms. Call an individual who contributes to an outcome 'a contributor' and someone who is affected by it 'a recipient.' Focusing on the harmful outcome, a recipient might ask: if it is wrong for an individual to affect us in this way, how could it not be wrong to do so in combination with others? A contributor, by contrast, will reflect on what she actually does as well as on her intention. From this perspective she might ask: if it is not wrong for me to do this in isolation, how could it be wrong when others do it as well? When treated as rhetorical questions, a recipient will embrace the maximal solution and a contributor the minimal solution. The problem, however, is that each of these perspectives is partial. In the following, I will attempt to reconcile them and formulate a moderate solution that does justice to both.

\section{The prospect account}

\subsection{A reconciliation}

The prospect account revolves around the notion of success. An action is successful precisely if it helps bring about the outcome at issue. In this context, 'to help' is a success verb. It means that the outcome actually materializes and that this is at least partly due to what the relevant agent did. More precisely, an agent helps to bring about an outcome precisely if, given the dispositions of the others, her action is sufficient for the outcome. Suppose that in Three Nurses each of the three nurses is disposed to administer his medicine. In this situation, Noah's contribution is sufficient for the outcome given Omar's and Pablo's dispositions. Note, however, that Omar's contribution is also sufficient for the outcome given Noah's and Pablo's

\footnotetext{
7 According to the strongest conception of causal control, the agent's action must be necessary and sufficient for the outcome. A weaker conception requires only sufficiency (Alvarez, 2009). A causal contribution is a NESS-condition for the outcome (note 3).
} 
dispositions. By the same token, Pablo is in a position to help save the patient. Thus, if she is saved, each of their actions is successful.

Instead of success as such, the prospect account requires that the prospect of success be good enough. How likely an outcome is, depends on the behavioral dispositions of the relevant people and how easily they are triggered. Furthermore, the relation between individual behaviors and collective outcomes will often be probabilistic. As a first approximation, the prospect is good enough when it is sufficiently likely that the outcome will materialize and the agent has enough reason to believe that this is the case. The words 'sufficiently' and 'enough' reveal that both the causal and the epistemic conditions feature thresholds. These thresholds need not be high. 'Sufficiently likely' is equivalent to 'not too unlikely,' and 'enough reason' is equivalent to 'not too little reason.' I would use these reformulations if they were not so cumbersome.

How high the thresholds are is determined by the moral significance of the outcome. In this respect, they are normative. This feature of the prospect account enables it to reconcile the two perspectives just discussed. To explain how, I start by illustrating the fact that some contributory obligations are more demanding than others. Consider the following two examples, one about a child who loses a teddy bear and another about a lost child:

Lost Teddy Bear. A child visits a mall with her parents and loses her teddy bear. The parents trace their steps, and lots of people in different places help them look for it.

Lost Child. A child visits a mall with her parents and gets lost. The parents trace their steps, and lots of people in different places help to look for her.

Now, suppose that in each case the people spend an hour searching the mall without finding the teddy bear/child. At that point, it is most likely that the bear/child has been taken by someone. As the people involved know, the probability of finding it/ her outside the mall is small. In this situation, it seems acceptable to call off the search effort for the teddy bear. At the same time, it would be outrageous to stop looking for the child. The disappearance of a child warrants an organized search party that stretches over days.

This difference in terms of how demanding the obligations are can be explained by invoking thresholds. After an hour, people are no longer required to continue looking for the teddy bear. The probability of success is too low. Now, the probability of finding the child is the same. In spite of this, it is still high enough to continue looking for her. It seems plausible that in each case there are thresholds below which contributing to the search is not required. Furthermore, the thresholds are much lower in the case of the child compared to the teddy bear case, as is suggested by the difference in effort required for searching for them. But what explains this contrast? The only difference between the two examples concerns what is lost, the teddy bear and the child. Clearly, the moral significance of finding the child is higher than that of finding the teddy bear. Thus, I propose, the difference between these examples is to be explained in terms of normative thresholds, which are lower when the significance of the outcome is higher. 
Reconciling the recipient and contributor perspectives requires rejecting the extreme solutions. The core claim of an intermediate or moderate alternative is this: in insignificant hands situations, contributing can, but need not, be obligatory. This splits the difference between the two perspectives. As such, it enables recipients and contributors to meet each other half way and to surpass the partiality of each of their viewpoints. Extreme and moderate solutions differ at a more fundamental level, however. The extreme solutions assume INDEPENDENCE ${ }^{8}$ :

[INDEPENDENCE] Whether an agent ought to contribute is independent of whether others are disposed to do so.

Moderate solutions assume INTERDEPENDENCE instead:

[INTERDEPENDENCE] Whether contributing to an outcome is obligatory can depend on whether others are disposed to do so.

Derek Parfit supports INTERDEPENDENCE when he argues that 'even if an act harms no one, this act may be wrong because it is one of a set of acts that together harm other people' (1984, p. 70). ${ }^{9}$ Furthermore, he proposes that the extent to which the members of a group believe that enough others will act a certain way can be relevant to whether they ought to do so (1980, pp. 77-78). Reconciling the two perspectives requires embracing INTERDEPENDENCE.

The notion of a normative threshold gives further substance to the proposed reconciliation. The prospect account entails that recipients do not have legitimate grounds for blaming an individual when the prospect of helping to prevent the harm is too low. Conversely, contributors cannot claim the moral high ground when their contributions are sufficiently likely to add up to a harmful outcome. In this way, the prospect account provides a coherent outlook on collective significance and individual insignificance, the two defining features of the problem of insignificant hands. Nevertheless, it needs to be developed in more detail in order to see whether it can deliver on its promise.

\subsection{The solution}

The prospect account concerns moral norms about benefits and harms, such as 'Do no harm.' Both the presence of benefits and the absence of harms constitute morally desirable outcomes. Moral norms come with application conditions that specify

\footnotetext{
${ }^{8}$ INDEPENDENCE is entailed by Murphy's (2000) compliance condition. His initial gloss of this condition is: 'The demands on a complying person should not exceed what they would be under full compliance with the principle.' (1980, p. 7) This seems to allow for the possibility that it would be permissible to do less under certain circumstances. However, according to the final formulation of the principle, it 'requires an agent to do the same thing under partial as under full compliance.' (1980, p. 86) This entails that the agent ought to do no more and no less than her fair share. See note 19 for a criticism of the compliance condition.

9 See also Braham and Van Hees (2012), Spiekermann (2014), Pinkert, (2014) and Nefsky (2017).
} 
when a moral agent has the obligation that features in the norm. ${ }^{10}$ The prospect account explicates those application conditions. It thereby delineates which contributions are obligatory. The prospect account consists of two causal conditions and one epistemic condition [PROSPECT]: ${ }^{11}$

[PROSPECT] A moral agent has a pro tanto obligation to contribute to an outcome $O$ that has moral significance $\omega$ by performing an action $A$ that has morally relevant costs $\alpha$ exactly if:

1. $A$ increases the probability of $O$ to a sufficient extent, given $\alpha$ and $\omega$.

2. The probability of $O$ is high enough, given $\alpha$ and $\omega$.

3. The agent has adequate reason to believe that $O$ has moral significance $\omega$, that $A$ has morally relevant $\operatorname{costs} \alpha$, and that 1 and 2 , given $\alpha$ and $\omega$.

Each of these three conditions features a threshold that depends on the moral significance of the outcome and on the morally relevant costs of the action. These two factors determine whether the probability increase is sufficient, the total probability is high enough, and the agent has adequate reason to believe that these things are the case.

According to condition 1, the agent has to be in a position to perform an action that increases the (objective) probability of the outcome to a sufficient extent. ${ }^{12}$ And according to condition 2, the total probability must be high enough (not too low). Both conditions can be illustrated by Lost Teddy Bear and Lost Child, given that the moral weight of finding the child is substantially higher than that of finding the teddy bear. Suppose there is someone who could join the search party. It might be that the extent to which his efforts would increase the probability of success is not high enough for him to be obligated to search for the teddy bear, even though it is more than high enough to sustain an obligation to search for the child. Similarly, the total probability of success might be too low if the teddy bear is outside of the mall, whereas it will be high enough for people to be obligated to search for the child in the area. ${ }^{13}$ Together, these two conditions form what I call 'the causal prospect proviso.' 14

\footnotetext{
${ }^{10}$ A moral agent possesses normative competence. This means that they are able to attend to moral issues in their thinking, decision-making and actions (Wallace, 1994; cf. Fischer and Ravizza, 1999). For the purposes of this paper, this generic characterization suffices.

${ }^{11}$ Sometimes an agent can contribute to $O$ in several ways. Ceteris paribus, an action will be required if it increases the probability of $O$ more than another.

${ }^{12}$ See Vallentyne (2008) for an account of degrees of responsibility that features objective probabilities.

${ }^{13}$ In some cases, the total probability threshold will be met precisely because of the contribution of a particular agent. Condition 2 is then satisfied in part because condition 1 is met.

${ }^{14}$ Lawford-Smith (2015a; b) and Collins (2019) argue that people ought to signal their conditional willingness to contribute to the outcome. Their willingness becomes unconditional only when enough others have done the same, such that their combined efforts suffice to bring about the outcome. This condition is significantly more demanding than the causal prospect condition. It implies that an individual must be in a position to help bring about the outcome, whereas I require only that the prospect of this being the case is good enough (which it might be, even if it is low).
} 
Condition 3 is 'the epistemic prospect proviso.' It requires that the agent have enough reason to believe that conditions 1 and 2 are met and that the two normative factors are what they are. An agent can have enough reason to believe that there is a harm pending without being aware of it, for instance. But does he also have enough reason to believe what its moral significance is and what the morally relevant costs are? I believe so. The idea is that if the agent were to check, he would in all likelihood find out what it is.

Together, the causal prospect proviso and the epistemic prospect proviso specify when the prospect of success is good enough. Furthermore, they support what I call 'the prospect range.' Any and all contributions that fall within it are in principle required. The prospect range is determined by the three thresholds that feature in the three conditions of PROSPECT. The lower limit of the prospect range consists of those contributions that the agent has just enough reason to believe will barely pass the causal thresholds. The upper limit consists of those contributions that the agent has just enough reason to believe will generate the smallest non-negligible increase in probability. Beyond that point, further contributions are not worthwhile. Thus, the prospect range delineates which contributions are required.

Christopher Morgan-Knapp and Charles Goodman maintain that 'a constraint against harming can't prohibit doing something harmless' (2015, p. 179). They assume that the norm applies only to agents who consider performing an action that causes harm. Although plausible on the face of it, this assumption makes it difficult, if not impossible, to solve the problem of insignificant hands. According to PROSPECT, the norm against harm applies to any agent who is in a position both to contribute to a harm and to refrain from doing so. This explains how the norm against harm can prohibit actions that are harmless in and of themselves. It thereby explains how the prospect account solves the problem of insignificant hands. To give it further content, I go on to discuss two causal considerations that, together with the normative and epistemic factors, determine the scope of the prospect range: the feasibility of the outcome and the possible redundancy of the contribution.

\section{Redundancy and feasibility}

\subsection{The efficacy argument}

The prospect account solves the problem of insignificant hands, or so I have argued. As the examples suggest, it does so in an intuitive manner. It is also theoretically appealing insofar as it provides a coherent outlook on collective significance and individual insignificance-the defining features of the problem. Because of this, it reconciles the perspectives of the recipients of and the contributors to harm. In this section, I defend PROSPECT in terms of what I call 'the efficacy argument.' This pertains to the feasibility of the outcome and the possible redundancy of the contribution in question, which I refer to as the 'efficacy considerations.'

Moral norms feature pro tanto obligations, which are 'presumptively decisive reasons' (Scheffler, 1997). A possible outcome generates such an obligation only if it is morally significant. However, there are also certain side constraints that have to 
be met. When pursuing a moral end, an agent must select suitable means, and what is suitable is sensitive to whether the outcome is feasible and to whether the action is redundant. When an outcome is not feasible, contributing to it is in a sense futile. To be sure, some redundancy can be a good thing, as it can serve to secure the outcome. Beyond a certain point, however, making a redundant contribution is pointless, and morality does not require people to perform actions that are futile or pointless. To be sure, whether a contribution is futile or pointless is a normative question. But there is ample reason to believe that the efficacy considerations should be considered when answering it. Thus, selecting a suitable means requires attending to the feasibility of the outcome and the redundancy of the contribution.

If they were not constrained by the efficacy considerations, contributory obligations would be overly demanding. The limits to the risks of infeasibility and redundancy are set by thresholds. They determine when those risks are acceptable. This explains why the thresholds depend in part on normative factors, to wit the moral significance of the outcome and the morally relevant costs of contributing. To be sure, the thresholds can be rather low. Even so, they must be suitably sensitive to the circumstances, including the efficacy of the relevant contribution. Although it should last a long time, even a search party for a lost child need not continue forever. Obligations come to an end somewhere, and their limits depend in part on the efficacy considerations. ${ }^{15}$

In order to get a better sense of how feasibility and redundancy bear on the obligations people have, I consider two variants of the problem of insignificant hands. The problem of too few hands concerns situations in which the number of individuals who are willing to contribute to an outcome is lower than the number that is needed to bring it about. The problem of too many hands, by contrast, pertains to situations in which the number of individuals who are willing to contribute to an outcome exceeds the number that is needed to bring it about. The former raises the question of feasibility, the latter that of redundancy.

\subsection{Too few hands}

In Three Nurses, neither feasibility nor redundancy is an issue. I will now introduce an example that has the same structure but that can easily be changed such that they become an issue:

Three Hikers. Three hikers, Aiko, Bartoli and Caleb, meet Delta, a severely dehydrated hiker. Each of the three hikers has drunk enough water to make it home safely. Delta will survive precisely if all three of them give her their remaining water.

Suppose each has finished half the bottle he is carrying. Then, the dehydrated hiker will survive precisely if she drinks three bottles that are half full. This somewhat artificial assumption is crucial at first, but I will relax it later. As an example of the

15 This is also supported by the fact that unilateral contributions to infeasible outcomes can backfire (Dietz, 2016; Pinkert, 2014). Redundant contributions can also have deleterious consequences (Goodin, 2012, p. 22n5). 
problem of too few hands, consider a variation on Three Hikers that is identical to it except for the following additional sentence:

The Unwilling Hiker. ... But Aiko is unwilling to do so.

As it happens, Aiko believes that giving his water to Delta will only prolong her suffering. Furthermore, he is not moved by claims to the contrary. Because of this, he is adamant about not parting from his water. His will not to do this is so strong that he cannot be convinced or persuaded to change his mind. In this situation, there are not enough willing hands. This means that, no matter what Bartoli and Caleb do, Delta will die. After all, even if they were to give their water to Delta, Aoki, the unwilling hiker, would not follow suit. In this situation, what is morally desirable is not feasible. Even so, it is possible for each of the three hikers to contribute. This raises the question of whether it is permissible to do nothing.

According to the maximal solution, what is obligatory is constrained by what is possible. Its key claim is that in principle, everybody who can contribute ought to do so. Absent special circumstances, its message is: contribute if you can. The moderate solution takes obligations to be constrained instead by what is feasible. In order for an outcome to be feasible, it must be possible in the circumstances at hand (Wiens, 2015). ${ }^{16}$ It is possible to climb Mount Everest, for instance, but it might not be feasible in the prevailing weather conditions. As Unwilling Hiker illustrates, what is feasible can also depend on what other people do. It is not feasible for Bartoli and Caleb to help save Delta, because, given the volitions he actually has, Aoki will not contribute. In the circumstances at hand, they cannot do anything other than take his unwillingness as given. However, when considering what is possible, volitions should not be regarded as fixed. Presumably, there is a possible world in which all three are willing to contribute. If so, saving Delta is possible.

It follows that, if contributory obligations depend on what is feasible, Bartoli and Caleb ought to give their water bottle to Delta in Three Hikers, but not in Unwilling Hiker. ${ }^{17}$ In contrast, if they depend on what is possible, then Bartoli and Caleb ought to give their water bottle to Delta also in Unwilling Hiker. However, doing so is beside the point, as there is no chance that they will help Delta by doing so. This illustrates how implausible it is to let infeasible outcomes determine what people ought to do. For Bartoli and Caleb, contributing is futile. And morality does not require people to perform actions that are futile, at least not in the sense at issue. ${ }^{18}$

Proponents of the maximal solution will object to this and argue that the fact that some flout their duty is no reason for others to do so. In other words, the fact that

\footnotetext{
${ }^{16}$ For an overview of the literature on feasibility, see Southwood (2018).

17 Collins (2019, pp. 119-20) defends a similar conclusion about the relation between a lack of willingness and the obligations people have.

18 It is worth emphasizing that I am concerned here with contributions that are futile ex ante rather than ex post. As I use the term here, a contribution is futile exactly if it concerns an outcome that is not feasible. In contrast, a contribution that someone actually makes will turn out to be futile if the morally significant outcome does not materialize. According to the prospect account, it could be that the probability of this happening is high. As the probability of success need not be high, the probability of failure can be.
} 
some are unwilling to contribute does not justify doing nothing. However, I am not committed to the claim that the moral failure of the one justifies the inaction of the other. Instead, I regard the fact that someone is unwilling to contribute as part of the circumstances that determine whether others are obligated to do so. Thus, rather than justifying it, the unwillingness of some explains why others are not obligated. The fact that the outcome is unattainable given the circumstances accounts for the fact that it is permissible to do nothing. From Bartoli and Caleb's perspective, it does not matter whether the obstacle is that Aoki is refusing to part with his water or that he has already drunk it. The crucial issue is that the outcome is not feasible. It follows that infeasible outcomes do not obligate. ${ }^{19}$

The core of the moderate solution can be captured as follows: contribute if the prospect of being instrumental to success is good enough. In order to apply this idea correctly, it is important to realize that what is feasible can differ between people. Suppose that Alejandra and Thiago have been practicing the Argentinean tango, but Thiago is no longer willing to participate in the upcoming contest. Because it is too late for Alejandra to find another partner, it is infeasible for her to participate. If Alejandra is still willing to team up with him, however, it is feasible for Thiago to participate. Thus, the relevant notion of feasibility is agent-relative. This is of crucial importance for the relation between feasibility and obligation. As just discussed, saving Delta is not feasible relative to Bartoli and Caleb. However, it is feasible for Aoki. After all, if he were to contribute, the other two would do so as well, and Delta would be saved. In light of this, I propose that Aoki has a contributory obligation, while, in the current circumstances, it is permissible for Bartoli and Caleb to do nothing. ${ }^{20}$

According to INTERDEPENDENCE, contributory obligations can depend on the behavioral dispositions people have. This is supported by Unwilling Hikers, as it reveals that it can be permissible to refrain from contributing because others are not disposed to do so. More colloquially, it can be permissible to do nothing because others are doing nothing (Björnsson, 2014; Dietz, 2016). In light of this, I propose that feasibility is a necessary condition for obligation. This is captured by what I call 'the ought-implies-feasibility principle' $[O I F]$ :

$[O I F]$ An outcome obligates an agent only if it is feasible relative to the agent.

Importantly, $O I F$ differs from the ought-implies-can principle $(O I C)$. According to $O I C$, an agent is obligated to do something only if she is able to do it (Vranas, 2007). Whereas $O I C$ concerns the possibility of the action, OIF pertains to the feasibility of the outcome. All of the examples in this paper satisfy $O I C$ because in each of them every individual is in a position to contribute. OIF is not satisfied in Unwilling Hiker, however, because too few are willing to do so. Note that this

\footnotetext{
19 Karnstein (2014) voices basically the same objection with respect to the fair share view mentioned in note 8. Although unfairness is of course a serious issue, it concerns duty bearers among each other. As such, it should be kept distinct from our obligations to third parties (1980, p. 607). Those obligations are determined by the actual circumstances, which include the inaction of other people (1980, p. 597).

20 See Dowding and Van Hees (2007) for a discussion of the test of counterfactual success on which I rely here.
} 
changes as soon as there is some probability that Delta will survive if she only drinks two half-full bottles of water. ${ }^{21}$

According to Julia Nefsky (2017), individuals who do not have an obligation to contribute can still have reason to do so, even though this reason may be very weak. An individual has reason to contribute, she proposes, whenever his action plays 'a non-superfluous causal role in the occurrence of an outcome' (1980, p. 2746), and an action is superfluous when it is not the case that the outcome could fail to materialize due to a lack of acts of that type (1980, p. 2753). It follows that an action can be non-superfluous even when the outcome is extremely unlikely and might not occur at all. Whether an action is non-superfluous depends in part on what others will do (1980, pp. 2762-63). This suggests that Nefsky's claim should be reformulated as follows: an individual has reason to contribute to a morally desirable outcome whenever that outcome is feasible. The underlying idea is that in such situations, he might help bring it about. ${ }^{22}$

According to the prospect account, however, an individual has no reason to contribute at all when the prospect of helping to bring about the outcome is not good enough. Moral norms feature pro tanto obligations, and an individual has such an obligation only if the norm applies to him. This requires that PROSPECT's conditions be met. Conversely, when an individual does not have a pro tanto obligation, she has no reason to contribute at all. When the applicability conditions of the norm fail to be met, the norm does not apply, which means that there is no reason for the agent to contribute. The upshot is that feasibility is insufficient for contributory obligations (and contributory reasons more generally). It is necessary, however. This insight solves the problem of too few hands. It entails that when there are too few hands, none of the relevant individuals is obligated to contribute.

\subsection{Robust and provisional unwillingness}

One might worry, however, that the prospect account lets people off the hook too easily. This concern is particularly pressing in Unwilling Hiker because there is enough water to save the dehydrated hiker. I will assume that Aoki is so strong that Bartoli and Caleb are unable to take the water from him even by force. This allows me to focus on the question whether Bartoli and Caleb should try to convince or persuade Aoki to part with his water. Earlier, I supposed that Aoki is unwilling to give his water to Delta because he believes that doing so will only prolong her suffering. Suppose that Bartoli is a physician and that he knows for a fact that this is not the case. Presumably, he should use this information to get Aoki to change his mind.

\footnotetext{
21 Even though it is a necessary condition for contributory obligations, the feasibility of a morally desirable outcome is not sufficient. According to the prospect account, such an outcome obligates only if the prospect of success is good enough.

22 Nefsky claims that the outcome has to be possible in the way that term is used in contexts of practical deliberation,' which means that it is restricted to 'live possibilities' (2017, p. 2760) This fits well with the idea that she is concerned with what is feasible, which is a subset of what is nomologically possible. Note, however, that Nefsky (2017, p. 2761) leaves open whether the relevant notion of possibility is epistemic.
} 
At this point, it is important to make a distinction between being robustly unwilling and being provisionally unwilling. In Sect. 4.2, I assumed in effect that Aoki is robustly unwilling. But suppose that he is provisionally unwilling instead and can be convinced to contribute. In that situation, the outcome remains feasible. Bartoli can now increase the probability that Delta will be saved by convincing Aoki. Presumably, he should do so. In light of this, I propose that people can have a duty to mobilize others. ${ }^{23}$

To mobilize someone is to activate that person. Doing so enlarges the number of individuals who are willing to contribute to the outcome. The point of doing so is to increase the probability that the outcome will materialize. Mobilizing typically requires that an individual communicate her willingness to him, if not make it public. Doing so can make the act of activating the other more credible. Furthermore, it can provide others reason to believe that the probability that the outcome materializes is higher than they thought before. Suppose that someone who was mobilized by someone else contributes to the outcome. Then, I will say, her act of mobilizing him constitutes an indirect contribution to the outcome. Direct contributions, by contrast, are not mediated by other individuals.

Just like direct contributions, indirect contributions are required only if their prospect is good enough. Compare two versions of Joyguzzlers: in the first version, the protagonists are climate change skeptics; in the second, they are climate change believers. It will be very difficult to convince or persuade joyguzzlers who are climate skeptics to refrain from that activity. However, climate change believers might already feel guilty about owning a gas guzzler. Perhaps they have even developed an interest in electric cars. It may well be that, due to this difference in circumstances, the prospect of mobilizing is good enough only in the second version of the scenario, which would mean that mobilizing others is required when joyguzzlers are climate change believers. The key point is that the prospect of indirect contribution may be good enough even if that of direct contribution is not. ${ }^{24}$

Can the proponent of the maximal solution embrace this proposal? The idea would be that in principle, everybody ought to contribute both directly and indirectly. The problem is, however, that the duty to mobilize often arises because others are unwilling to contribute. Someone who is committed to INDEPENDENCE cannot accept this. Consider, however, someone who has no reason to believe that she can contribute to a morally significant outcome. Someone else who knows about it can bring it to her attention. In such a case, someone who is committed to INDEPENDENCE can coherently embrace the idea that this individual is obligated to make an indirect contribution.

The prospect account takes the idea two steps further. Not only does it support obligations to contribute indirectly when others flout their obligations. But it also allows for the possibility of someone's having a duty to mobilize others without

\footnotetext{
${ }^{23}$ Elsewhere, I refer to the combination of the obligation to mobilize and the obligation to contribute to a collective outcome as 'the duty to join forces' (Hindriks 2019). For related ideas, see Lawford-Smith (2015a) and Collins (2019). For an important difference, see note 14.

24 Mobilizing others need not be a matter of having a one-off conversation with someone. It can also be an extended process during which the relevant action becomes moralized (Hindriks forthcoming).
} 
having an obligation to contribute directly. This is the case when, at that point, the prospect of the latter is too low, whereas the prospect of the former is good enough. It might be, for instance, that citizens do not have an obligation to refrain from joyguzzling, while they do have an obligation to get their government to make it illegal. As mentioned in note 5, Sinnott-Armstrong embraces both of these claims. However, it is not at all obvious that he can do so coherently.

Sinnott-Armstrong (2005) rejects the claim that individuals have an obligation to contribute directly because they do not have control over the outcome-to harms caused by greenhouse gasses. At the same time, he affirms the claim that they have an obligation to contribute indirectly by engaging in political action-the point of which is to mobilize or activate the government. The problem with this is that individuals do not control the outcomes of such actions either (Hiller, 2011, pp. 364-65). It follows that, if direct contributions are not required because individuals lack control, then making an indirect contribution is not obligatory either. Thus, Sinnott-Armstrong's attempt to mitigate his skepticism about climate duties fails. This in turn means that, on pain of incoherence, he is committed to the minimal solution without qualification.

But how can I combine these claims, while Sinnott-Armstrong cannot? The reason for this is that I do not insist on control. Instead, the causal condition of the prospect account concerns two probabilities: the probability that the outcome materializes and the extent to which that probability increases due to the individual at issue. These have to be high enough, given the moral significance of the outcome and the moral costs of the action. It is important to see that it is an empirical question how high they actually are. Suppose that the government is already leaning towards prohibiting joyguzzling. Then it is pretty likely that, by engaging in political action, an individual helps to make it the case that the government bans it. And it could be that the number of individuals needed for achieving this is relatively small such that the extent to which the probability of success increases by a single action is fairly large. In contrast, the probability to resolve climate harm by refraining from joyguzzling might be miniscule. Now, under these circumstances, it may well be that joyguzzling fails to meet the thresholds, while political action satisfies them. If this is indeed the case, only the latter is obligatory.

Thus, the duty to mobilize widens the scope of the prospect account. It does justice to the idea that it is rarely acceptable to do nothing. Furthermore, it supports the idea that, even if contributing directly is pointless, contributing indirectly might not be.

\subsection{Too many hands}

To investigate redundancy, I consider the problem of too many hands. This concerns situations in which the number of willing individuals exceeds that required to bring about the outcome. If everybody were to contribute in 'too many hands cases,' some contributions would be redundant. The question I am asking is whether all of the available individuals are obligated to contribute. Consider the following variation on Three Hikers: 
Thousand Hikers. A thousand hikers meet Delta, a severely dehydrated hiker. Each of the thousand hikers has drunk enough water to make it home safely. Delta will probably survive if three hikers give her their remaining water. Her survival will be robustly secured if seven individuals give her their remaining water. However, because the presence of so many people has taken its toll on Delta, each of the thousand hikers must act immediately.

Because they need to act immediately, the hikers cannot wait and see how many others will contribute. They must decide all at once and give their bottles to Delta at the same time. Furthermore, there is nothing that distinguishes the thousand individuals from each other. In this situation, all of them are obligated to contribute. After all, the moral significance of a life is rather high, and the costs are negligible, if not morally irrelevant.

Suppose, however, that Thousand Hikers continues as follows:

Thousand Hikers*... As it happens, each individual is wearing a T-shirt with a number. For any number $n$, there are $n$ individuals who are wearing a T-shirt with that number.

The maximal solution does not distinguish between these two versions of the scenario. It requires everybody to contribute in both. However, the numbers on the T-shirts provide a way to limit the number of contributions. Because of this, on the prospect account there are fewer obligations in the second version than in the first, at least if the hikers appreciate that they can use the T-shirts to coordinate their efforts.

They might do so if it is common knowledge that seven bottles will secure Delta's life. Against this background, T-shirts with the number seven may well become salient. Because they form a focal point or function as a correlating device, people may infer that their contributions are a means to saving Delta, such that it becomes common knowledge (Gintis, 2007; Lewis, 1969; Schelling, 1960). ${ }^{25}$ If this is the case, the individuals who wear them thereby become obligated to give their water to Delta. At this point, the idea of a thousand hikers having to give their water to Delta starts to look a bit silly. Just picture a pile of hundreds of bottles next to Delta. As the size of this pile vividly illustrates, many contributions will be redundant. If everybody were to contribute, 993 contributions would be beside the point. There seems to be no reason to believe that morality requires the hikers to overshoot in such a dramatic manner.

In this way, PROSPECT can limit the number of redundant contributions. Whether it does so is contingent on the availability of a suitable method for selecting contributions that are required. Such a method decreases the prospect range. A contribution that goes beyond this range is both redundant and pointless. Strikingly, in Thousand Hikers no contribution is pointless, while in Thousand Hikers* any contribution beyond seven is. In this way, PROSPECT solves the problem of too many hands.

\footnotetext{
${ }^{25}$ See Pinkert (2014) for more on salience in relation to collective action.
} 


\section{Consequentialism and deontology}

Because it is sensitive to the efficacy considerations, one might think that PROSPECT offers a consequentialist solution to the problem of insignificant hands. However, as John Rawls pointed out, 'all ethical doctrines worth our attention take consequences into account in judging rightness' (1971, p. 26). In this section, I explore whether the prospect account is consistent with deontology and consequentialism. I refer to prospect deontology as ' $P R O-D E O$ ' and to prospect consequentialism as 'PRO-CON.' As it turns out, the prospect account is consistent with normative theories of any kind except act consequentialism. As it turns out, the prospect account is inconsistent with all normative theories other than act consequentialism.

\subsection{PRO-DEO}

According to a popular interpretation, Kant holds that whether an agent ought to contribute is independent of whether others are disposed to do so. This means that he is committed to INDEPENDENCE. On this interpretation, 'minding your own business is all a person is morally required to do' (Lichtenberg, 2015, p. 558). In line with this, Kant is commonly taken to support unilateral cooperation in a prisoner's dilemma. ${ }^{26}$ The notion of unilateral cooperation also plays a central role in what is widely regarded as the Kantian solution to the tragedy of the commons: "every commons user ought, morally, to restrict his or her use to a level that would be sustainable if all other users reduced their use in a similar way, and to do this regardless of what others do' (Johnson, 2003, p. 272). ${ }^{27}$ On this interpretation, what is required in a situation is determined by what is possible, not by what is feasible. The underlying idea is that people must act from duty and that doing so does not require attending to considerations of efficacy. It seems to follow that Kantians must support the maximal solution. Because this is one of the two extreme solutions, I refer to this reading of Kant as 'the extreme interpretation.'

The problem with this interpretation is that it does not pay the distinction between maxims and actions its due. Kant's (1998/1785) Formula of Universal Law $(F U L)$ applies to maxims. There is some controversy over how exactly this should be interpreted, however. Onora O'Neill (2004) proposes that it requires people to act on maxims that can be willed by all. Pauline Kleingeld (2017) argues instead that one should act on maxims that one can will as a universal law and as one's own law simultaneously. Along with many others, O’Neill regards the FUL as a universalizability test. Kleingeld, by contrast, takes it to be a test of volitional self-

\footnotetext{
${ }^{26}$ See, for instance, Sen (1974, p. 76) and Binmore (1994, pp. 154-57). For a qualified version of this claim, see Braham and Van Hees (2015, p. 257).

27 Johnson criticizes this proposal: 'it is a mistake to see our primary obligation as unilaterally reducing our individual burden on the environment' (2003, p. 286). He rejects it because of a concern with feasibility: 'At least in addressing commons problems, unilateral, voluntary actions typically have no reasonable chance of achieving their object' (2003, p. 272). Instead, he argues, people should formulate an agreement and enforce it. As it happens, this may well be consistent with Kant (1998/1785).
} 
contradiction. What these interpretations have in common is that they take the FUL to be concerned with what is possible, not what is feasible. This strongly suggests that, at this stage, Kant presupposes INDEPENDENCE. However, checking whether a maxim conforms to the FUL is only one out of two steps that need to be taken in order to determine what is required in a particular situation. ${ }^{28}$

When someone could contribute to a possible morally significant outcome, she should consider maxims that feature this outcome. She should adopt a maxim that is consistent with the FUL. The second step is that of applying the relevant maxim to the relevant situation. This is a matter of translating it into action, of identifying the action that the maxim requires in the situation at hand. Doing so requires considering the contingencies of the situation. At this point, the efficacy considerations can and often should enter into the equation. Crucially, this means that INDEPENDENCE plays no role during this second step. Kant relies on it only when testing maxims. When determining which actions are obligatory in practice, he relies in effect on INTERDEPENDENCE. It is easy to lose sight of this because this second step is trivial in cases such as lying and promising. It makes a difference when benefits and harms are concerned, however. The upshot is that what is possible determines which maxims are valid, while what is efficacious bears on which actions they mandate. According to what I call 'the moderate interpretation,' Kant supports a moderate solution.

In Sect. 4.2, I argued that it is permissible to do nothing both in Unwilling Hiker and in the version of Joyguzzlers in which they are climate change skeptics. If the prospect account is to be consistent with the moderate interpretation of Kant, the two views should converge on the same verdicts in these cases. In the hiker examples, the relevant maxim is 'Prevent harm.' (To the extent that it concerns rescue cases, it can plausibly be taken to support perfect duties.) Suppose that, in Unwilling Hiker, Bartoli gives his water to the dehydrated hiker. Does he thereby act according to this maxim? Although he contributes to this goal, there is no chance that he will thereby help to save Delta. Hence, he cannot plausibly be taken to satisfy the maxim.

In Joyguzzlers, the relevant maxim is 'Do no harm.' I have argued that, when too few others refrain from joyguzzling, it is permissible for others to continue to engage in this activity. This is a more daring claim, because they are, in a sense, contributing to a harmful outcome. Apart from the fact that they do not do any harm themselves, however, they have no reasonable prospect of helping to prevent harm, even indirectly. To be sure, individual joyguzzlers may well have good reason to stop engaging in this activity. All I claim is that these will not be connected to outcome responsibility. Thus, in neither of these cases does acting in accordance with the maxim require the relevant individuals to contribute to the outcome. It follows that the Kantian verdicts and those of the prospect account do indeed converge.

\footnotetext{
28 Sandler argues that Kantianism cannot accommodate unintended consequences because they 'are not a necessary means to the ends sought' (2009, p. 173). For instance, 'the continuing buildup of greenhouse gases in the atmosphere is not sought by those whose actions contribute to it, nor is it a means to any end that is sought' (1980). On my interpretation, an individual should consider those consequences and ask whether contributing to them is permitted by a maxim that accords with the FUL. In this way, Kantianism does take unintended consequences into account.
} 
According to Kantians, purely subjective costs do not count. For instance, the fact that an action inconveniences an individual is morally irrelevant. Recall, however, that in Lost Child a couple other than the parents of the child helps to look for her for hours. At some point, they decide to go home and cook dinner for their own children. Now the Kantian could recognize the children's hunger as a valid consideration that limits the extent of the obligation to help look for the lost child. And it might be that, because of this consideration, the couple can justifiably stop participating in the search. It follows that there is a limit to the sacrifices someone can reasonably be expected to make for the sake of another, especially when the prospect of success is low. ${ }^{29}$ Now I am not, of course, claiming that Kant (1998/ 1785) had PROSPECT in mind when he developed his ideas about FUL. Instead, the idea is that due to structural similarities, Kantians can coherently adopt the prospect account.

Next, consider contractualism. According to Thomas Scanlon (1998, 2011), a moral principle is valid precisely if no one can reasonably reject it. An individual can object to a principle when he is burdened by it as long as he does so in terms of considerations that can be evaluated by relying 'on commonly available information about what people have reason to want' (Scanlon, 1998, p. 204). Although it abstracts from specific features of particular individuals, contractualism takes people's actual circumstances, including their interests, into account right from the start. When a principle benefits one individual and burdens another, the question is whether the burdening of the one constitutes a legitimate ground for rejecting it, given the benefit to the other. This requires considering 'the weightiness of the burdens it involves, for those on whom they fall, and the importance of the benefits it offers, for those who enjoy them, leaving aside the likelihood of one's actually falling in either of these two classes' (1980, p. 208).

As an example of a burden that does not provide a legitimate ground for complaint, suppose that a principle burdens someone, but every alternative imposes a greater burden on someone else. Because of the latter, the former does not constitute a valid objection to the principle at issue (Ashford and Mulgan 2018). In Thousand Hikers*, 993 hikers could reasonably reject the principle that each must contribute, given that it burdens them without benefiting anybody. Suppose that, in Joyguzzlers, several lives are at stake. Contractualism does not allow for the consideration of their combined significance. Instead, the benefit of a single life is to be compared to the burden that a prohibition on joyguzzling would impose on a single joyguzzler. Scanlon considers redundancy explicitly when he argues that when more people can contribute than are needed, it is permissible for some not to do so as long as there is 'some fair mechanism for deciding who should be released from contributing' (1980, p. 213). Scanlon's own example is rolling a die. Relying on numbered T-shirts is a fair selection procedure as well. Those wearing a T-shirt with the number 7 on it cannot reasonably reject a principle that requires them to contribute. Had some other number been effective and salient, others would have

\footnotetext{
${ }^{29}$ Korsgaard (1996) recognizes morally relevant costs, although the bar that she sets seems to be rather high. On her view, something that thwarts the agent's life plan is an issue worthy of moral concern.
} 
incurred the burden. Furthermore, there is no less burdensome method for saving the life of the dehydrated hiker.

Contractualism takes the prospect of success into account in other respects as well. First, there is a limit to the burden that an individual can reasonably be expected to bear. For instance, the Rescue Principle features a 'moderate ... threshold of sacrifice' (Scanlon, 1998, p. 224). This threshold depends in part on the benefit that someone else will incur. Second, there is a limit to 'the level of care' an agent ought to display, for instance, when it comes to the duty not to harm (1980, p. 209). Drivers, for example, ought to take reasonable precautions, such as observing the speed limit. With this said, the cost of eliminating the risk of harm altogether 'is too high' (1980). Thus, it would be pushing things too far to prohibit driving altogether. ${ }^{30}$ Both features - the limited burden and the limited level of care-support the requirement that a probability increase must be sufficiently high (condition 1). The first feature also fits with the idea that, in an example such as Joyguzzling, the total probability of realizing the outcome can be so low that a principle that prohibits it can reasonably be rejected (condition 2). In this way, it does justice to the consideration of feasibility. At the same time, contractualism can also require people to mobilize others and increase the probability of success. The upshot is that contractualism comes with an inbuilt concern for both efficacy considerations. This means that there are at least two ways of developing a plausible version of $P R O-D E O .^{31}$

\subsection{PRO-CON?}

According to Consequentialism, an act is required precisely if it generates a higher sum of benefits over costs compared to the available alternatives. From this perspective, the core problem is that most individual contributions to collective outcomes have costs but no benefits. Consider flying. Refraining from flying is costly. In addition, the chances that my refraining from buying a ticket will result in the flight's being canceled are slim. In other words, the probability of my being 'the threshold passenger' is very low. In light of considerations such as this, MorganKnapp and Goodman conclude, for the case of climate change, that 'actconsequentialism cannot provide a moral reason for individuals to voluntarily reduce their emissions' (2015, p. 177).

The natural step is to adopt a version of consequentialism that invokes expected consequences. The expected benefits of a contribution are calculated by multiplying the utility of the outcome by the probability of bringing it about, or rather the extent to which an action increases its probability. Its expected value consists of the

\footnotetext{
${ }^{30}$ Ashford and Mulgan (2018, Sect. 11) argue that contractualism is committed to prohibiting risky social activities such as driving because it abstracts from the probability with which an agent incurs a burden. However, Scanlon (1998, p. 209) regards this probability as irrelevant only to determining the significance of the objection. He does take it to bear on the measures people should take to reduce the risk of the burden.

${ }^{31}$ Perhaps Rossian value pluralism provides a suitable basis for developing a third version of PRO-DEO (Ross, 1930; Williams, 1981).
} 
expected benefits minus the expected costs of contributing. Even when only one contribution makes a difference, all of them can have a positive expected utility. Shelly Kagan (2011) invokes this idea in an attempt to solve the problem of insignificant hands. As an example, he considers animal suffering:

Threshold Chicken. A butcher sells chickens that have suffered. When he has sold 25 chickens, he orders another crate of chickens. Thus, the 25th customer who buys a chicken triggers a new order.

In this situation, buying a chicken has a negative utility only when doing so triggers a new order. However, customers do not know whether their purchase will do so when they are considering buying a chicken. Suppose that the utility of consuming a chicken is rather low in comparison to what the chicken has suffered. Then, the expected utility of a purchase will be negative, because there is some probability that it will trigger the action. It follows that buying a chicken is impermissible for all. ${ }^{32}$

Depending on the circumstances, expected utility theory can be rather sensitive to the efficacy considerations. In Threshold Chicken, if 27 consumers who wanted to buy a chicken all refrained from doing so, 24 contributions would be redundant. Thus, the theory allows for contributions that are inefficacious. However, it will not require any contributions to outcomes that are expected to be infeasible or that are expected to be redundant. Neither increases the probability of the outcome. Thus, the theory does not regard any expected risk of overshooting or undershooting as morally acceptable. This matters greatly when consumers have more information. Suppose that the example continues as follows:

Labeled Threshold Chicken.* ... To keep track of when he should make a new order, the butcher tags the chickens he sells using consecutive number labels.

The number labels enable the customers to avoid performing a triggering action. In this situation, it is permissible to buy any chicken except the one labeled 25 . Thus, this version of the example reinstates the original problem. This reveals that, at least in some situations, expected utility theory is too sensitive to what others do. ${ }^{33}$

The verdicts that the prospect account supports are less volatile because of the thresholds it features. Because it assumes maximization, expected utility theory does not rely on thresholds. First, any action that increases the probability of an outcome might be required, no matter how small or how minimal the benefit. Thus, it does not systematically allow for probability increases that are insufficient and not worth the effort. Second, it does not take the total probability of the outcome into

\footnotetext{
32 See Budolfson (2019) for a critical discussion of this kind of calculation.

33 Expected utility theory is also rather sensitive to taste. There might be a chicken aficionado among the customers for whom the benefits of consuming a chicken outweigh the expected costs. If so, she is permitted to buy a chicken.
} 
account at all. Third, it does not feature an epistemic threshold. Hence, it is inconsistent with the prospect account.

But what about rule consequentialism? Many act consequentialists accept the idea that agents should make moral decisions in terms of rules justified by their consequences. What is distinctive of 'full rule consequentialism' is the further claim that rules justified by their consequences actually determine what is wrong (Hooker, 2016; Parfit, 2011). Its core commitment is that the maximization test applies to rules rather than actions. Because rules come with application conditions, I propose that the test should be applied to what I have called 'moral principles,' which consist of norms or rules combined with their application conditions. Parfit includes at least some such conditions when he proposes the following principle:

When (1) the members of some group would make the outcome better if enough of them acted in some way, and (2) they would make the outcome best if all of them acted in this way, and (3) each of them both knows these facts and believes that enough of them will act in this way, then (4) each of them ought to act in this way. (1984, pp..77-78)

A simplified version of this principle is: an individual is obligated to help make the outcome better if he believes that he can. This principle focuses on success rather than the prospect thereof. As such, it does not consider the entire prospect range. Because it presents only a sufficient condition, however, it is consistent with the prospect account.

Rules that take the efficacy considerations into account will have better overall consequences than rules that apply across the board. Because of this, the combination under consideration is promising. A first objection that needs to be considered is that when rule consequentialism considers what others are disposed to do, it collapses into act consequentialism (Sandberg, 2011, pp. 238-39). It does not do so when the application conditions feature thresholds, however. A second objection concerns the complexity of moral principles. Rule consequentialists tend to favor simple rules, the idea being that the costs of accepting and complying with them are low. Although the prospect account can apply to simple rules such as 'Do no harm,' its application conditions might be regarded as complex. The first thing to note, however, is that people may be more prone to accept moral principles that feature the application conditions of the prospect account precisely because they are sensitive to the efficacy considerations. They will want to avoid performing futile or pointless actions. Rule consequentialists should consider such indirect consequences as well. Secondly, it may be that conditions that are rather similar to those of the prospect account are already implicit in our practices. After all, it does not seem too farfetched to think that people are in fact sensitive to the prospect of success. The upshot is that there is a way to give content to PRO-CON after all. 


\section{Conclusion}

The problem of insignificant hands concerns collective outcomes that are morally significant and individual hands that are morally insignificant in and of themselves. I have asked whether and when people are required to contribute in situations that exhibit these features. According to the prospect account that I have presented here, an individual can indeed be required to contribute. This is not because in some miraculous way her contribution is morally significant after all. Instead, it is because a number of individual contributions can add up to a morally significant effect. Contributing is required when the prospect of this being the case is good enough.

In order for what I have called 'the prospect of success' to be good enough, three conditions have to be met. First, the contribution must increase the probability of the outcome to an extent that is non-negligible. Second, given this increase, the total probability must be high enough. Third, the relevant individual must have enough reason to believe that these two things are the case. What counts as enough depends on the moral significance of the outcome. What counts as negligible also depends on the morally relevant costs of the action. The prospect account supports a prospect range such that all and only the contributions within it are required. Because of this, it avoids the extremes, according to which almost nobody or almost everybody is obligated to contribute. As such, it provides a moderate solution to the problem of insignificant hands.

The prospect account fits well with intuitions about cases, including Lost Teddy Bear and Lost Child. Furthermore, it reconciles the two perspectives that, on their own, make the extreme solutions look appealing. It is also supported by the efficacy argument, which turns on the question of what counts as an appropriate means to a moral end. A fourth consideration that counts in favor of the prospect account is that it avoids being either over-inclusive or under-inclusive. It keeps the risk of failure and the risk of being superfluous within morally acceptable limits. It does so in part because it supports the idea that people can have an obligation to mobilize others. This serves to increase the probability of the outcome, and it brings within reach outcomes that would otherwise be infeasible.

Finally, the prospect account can be combined with a range of normative theories. To be sure, some deontologists reject the idea that people's obligations can be sensitive to compliance levels. Furthermore, because of their commitment to maximization, act consequentialists cannot embrace the thresholds that feature in it. The former theories are not sensitive to what others do at all; the latter are too sensitive. Even so, the prospect account can be combined with normative theories that are moderate in this respect. These include Kantianism, contractualism, and rule consequentialism.

Acknowledgements I thank Gunnar Björnsson for inspiring discussions on the topic of this paper and Martin van Hees for a combination of critical and constructive comments that have greatly improved it. For helpful comments and discussions, I also thank Olle Blomberg, Stephanie Collins, Niels de Haan, Pauline Kleingeld, Holly Lawford-Smith, Katharina Nieswandt, Abe Roth, Andreas Schmidt, Kai Spiekermann, Allard Tamminga, Peter Timmerman, and Bill Wringe. Finally, I gratefully acknowledge comments from audiences at the Annual Congress of the Canadian Philosophical Association in Montreal, June 2018, the Conference on Energy Justice and the Capability Approach in Malmö, 
September 2018, and the MANCEPT workshop on collective responsibility in Manchester, September 2019.

Open Access This article is licensed under a Creative Commons Attribution 4.0 International License, which permits use, sharing, adaptation, distribution and reproduction in any medium or format, as long as you give appropriate credit to the original author(s) and the source, provide a link to the Creative Commons licence, and indicate if changes were made. The images or other third party material in this article are included in the article's Creative Commons licence, unless indicated otherwise in a credit line to the material. If material is not included in the article's Creative Commons licence and your intended use is not permitted by statutory regulation or exceeds the permitted use, you will need to obtain permission directly from the copyright holder. To view a copy of this licence, visit http:// creativecommons.org/licenses/by/4.0/.

\section{References}

Alvarez, M. (2009). Actions, thought-experiments and the "Principle of alternate possibilities." Australasian Journal of Philosophy, 87(1), 61-81.

Ashford, E., \& Mulgan, T. (2018). Contractualism. Stanford Encyclopedia of Philosophy. https://plato. stanford.edu/entries/contractualism.

Binmore, K. G. (1994). Game theory and the social contract: playing fair. MIT Press.

Björnsson, G. (2014). Essentially shared obligations. Midwest Studies in Philosophy, 38(1), 103-120.

Braham, M., \& Van Hees, M. (2012). An anatomy of moral responsibility. Mind, 121(483), 601-634.

Braham, M., \& Van Hees, M. (2015). The formula of universal law: A reconstruction. Erkenntnis, 80(2), 243-260.

Budolfson, M. B. (2019). The inefficacy objection to consequentialism and the problem with the expected consequences response. Philosophical Studies, 176(7), 1711-1724.

Collins, S. (2019). Group duties. Oxford University Press.

Dietz, A. (2016). What We together ought to do*. Ethics, 126(4), 955-982.

Dowding, K., \& van Hees, M. (2007). Counterfactual success and negative freedom. Economics and Philosophy, 23, 141-162.

Fischer, J. M., \& Ravizza, M. (1999). Responsibility and control: A theory of moral responsibility. Cambridge University Press

French, P. A. (1984). Collective and corporate responsibility. Columbia University Press.

Gintis, H. (2007). The bounds of reason. Princeton University Press.

Goodin, R. E. (2012). Excused by the unwillingness of others? Analysis, 72(1), 18-24.

Hardin, G. (1968). The tragedy of the commons. Science, 162(3859), 1243-1248.

Hart, H. L. A., \& Honoré, A. M. (1959). Causation in law. Oxford University Press.

Hiller, A. (2011). Climate change and individual responsibility. The Monist, 94(3), 349-368.

Hindriks, F. (2018). Collective agents: Moral and amoral. Dialectica, 72(1), 3-23.

Hindriks, F. (2019). The duty to join forces: When individuals lack control. Monist, 102, 204-220.

Hindriks, F. (forthcoming). When to start saving the planet. Journal of Ethics and Social Philosophy.

Hooker, B. (2016). Consequentialism. Stanford Encyclopedia of Philosophy.

Johnson, B. L. (2003). Ethical obligations in a tragedy of the commons. Environmental Values, 12(3), 271-287.

Kagan, S. (2011). Do I make a difference? Philosophy and Public Affairs, 39(2), 105-141.

Kant, I. (1998/1785). Groundwork of the Metaphysics of Morals. In M. Gregor (Ed.). Cambridge University Press, Cambridge. https://www.cambridge.org/core/books/kant-groundwork-of-themetaphysics-ofmorals/6FB8B104B7417A1B83E4091003938A0C.

Kant, I. (2007). Groundwork of the Metaphysics of Morals. In M. Gregor \& J. Timmermann (Eds.), Cambridge University Press.

Kingston, E., \& Sinnott-Armstrong, W. (2018). What's wrong with joyguzzling? Ethical Theory and Moral Practice, 21(1), 169-186.

Kleingeld, P. (2017). Contradiction and Kant's formula of universal law. Kant-Studien, 108(1), 89-115. 
Korsgaard, C. M., \& Korsgaard, C. M. (1996). Creating the kingdom of ends. Cambridge University Press.

Lawford-Smith, H. (2015a). Unethical consumption and obligations to signal. Ethics and International Affairs, 29(3), 315-330.

Lawford-Smith, H. (2015b). What “We?” Journal of Social Ontology, 1(2), 225-249.

Lewis, D. K. (1969). Convention: A philosophical study. Harvard University Press.

Lichtenberg, J. (2015). Negative duties, positive duties, and the "New Harms." Ethics, 3(120), 557-578. https://doi.org/10.1086/652294.

List, C., \& Pettit, P. (2011). Group agency. Oxford University Press.

Mackie, J. L. (1974). The cement of the universe. Oxford University Press.

Mankiw, N. G. (2013). Macroeconomics (8th ed.). Worth Publisher.

Morgan-Knapp, C., \& Goodman, C. (2015). Consequentialism, climate harm and individual obligations. Ethical Theory and Moral Practice, 18(1), 177-190.

Murphy, L. B. (2000). Moral demands in nonideal theory. Oxford University Press.

Nefsky, J. (2011). Consequentialism and the problem of collective harm: A reply to Kagan. Philosophy and Public Affairs, 39(4), 364-395.

Nefsky, J. (2017). How You can help, without making a difference. Philosophical Studies, 174, $2743-2767$.

Nefsky, J. (2019). Collective harm and the inefficacy problem. Philosophy Compass, 14(4), e12587e12617.

Nolt, J. (2011). How harmful are the average American's greenhouse gas emissions? Ethics, Policy and Environment, 14(1), 3-10.

O'Neill, O. (2004). Kant: Rationality as practical reason. In A. R. Mele \& P. Rawling (Eds.), The Oxford handbook of rationality (pp. 93-109). Oxford University Press. https://doi.org/10.1093/oxfordhb/ 9780195145397.001.0001.

Ostrom, E. (2015). Governing the commons. Cambridge University Press.

Parfit, D. (1984). Reasons and persons. Oxford University Press.

Parfit, D. (2011). On what matters. Oxford University Press.

Pinkert, F. (2014). What We together can (Be required to) do. Midwest Studies in Philosophy, 38(1), $187-202$.

Rawls, J. (1971). A theory of justice. Harvard University Press.

Ross, W. D. (1930). The right and the good. Oxford University Press.

Sandberg, J. (2011). "My emissions make no difference": Climate change and the argument from inconsequentialism. Environmental Ethics, 33(3), 229-248.

Sandler, R. (2009). Ethical theory and the problem of inconsequentialism: Why Environmental ethicists should be virtue-oriented ethicists. Journal of Agricultural and Environmental Ethics, 23(1-2), $167-183$.

Scanlon, T. M. (1998). What We owe to each other. Harvard University Press.

Scanlon, T. M. (2011). How I am not a Kantian. In S. Scheffler (Ed.), Derek parfit. On what matters (pp. 116-139). Oxford University Press.

Scheffler, S. (1997). Relationships and responsibilities. Philosophy and Public Affairs, 26(3), 189-209.

Schelling, T. C. (1960). The strategy of conflict. Harvard University Press.

Sen, A. K. (1974). Choice, orderings and morality. In S. Körner (Ed.), Practical reason (pp. 54-67). Blackwell.

Singer, P. (2006). Ethics and climate change: A commentary on MacCracken Toman and Gardiner. Environmental Values, 15(3), 415-422.

Sinnott-Armstrong, W. (2005). It's not my fault: Global warming and individual moral obligations. In W. Sinnott-Armstrong \& R. B. Howarth (Eds.), Perspectives on climate change: Sciences, economics, politics, ethics (Vol. 5, pp. 293-315). Elsevier. https://www.emerald.com/insight/publication/doi/10. 1016/S1569-3740(2005)5

Southwood, N. (2018). The feasibility issue. Philosophy Compass, 13(8), 1-13.

Spiekermann, K. (2014). Small impacts and imperceptible effects: Causing harm with others. Midwest Studies in Philosophy, 38(1), 75-90.

Tannsjo, T. (1989). The morality of collective actions. The Philosophical Quarterly, 39(155), 221-228.

Thompson, D. (1980). Moral responsibility of public officials: The problem of many hands. American Political Science Review, 74(4), 905-916.

Vallentyne, P. (2008). Brute luck and responsibility. Politics, Philosophy and Economics, 7(1), 57-80. 
Van de Poel, I., Royakkers, L., \& Zwart, S. D. (2015). Moral responsibility and the problem of many hands. Routledge.

Vranas, P. B. M. (2007). I ought, therefore I can. Philosophical Studies, 136(2), 167-216.

Wallace, R. J. (1994). Responsibility and the moral sentiments. Harvard University Press.

Wiens, D. (2015). Political ideals and the feasibility frontier. Economics and Philosophy, 31(3), 447-477. Williams, B. (1981). Moral luck. Cambridge University Press.

Wright, R. (1988). Causation, responsibility, risk, probability, naked statistics, and proof. Iowa Law Review, 73, 1001-1077.

Publisher's Note Springer Nature remains neutral with regard to jurisdictional claims in published maps and institutional affiliations. 